\title{
DAM-BREAK SHOCK WAVES WITH FLOATING DEBRIS: EXPERIMENTAL ANALYSIS AND TWO-PHASE MODELLING
}

\author{
Stefano Mambretti, Daniele De Wrachien, Enrico Larcan
}

\section{Introduction}

A thorough understanding of the mechanism triggering and mobilising debris flow phenomena plays a role of paramount importance for designing suitable prevention and mitigation measures. Achieving a set of debris flow constitutive equations is a task which has been given particular attention by the scientific community [31], [12], [43]. To properly tackle this problem relevant theoretical and experimental studies have been carried out during the second half of the last century.

Research work on theoretical studies has traditionally specialised in different mathematical models. They can be roughly categorized on the basis of three characteristics: the presence of bed evolution equation, the number of phases and the rheological model applied to the flowing mixture [23].

Most models are based on the conservation of mass and momentum of the flow, but only a few of them take into account erosion / deposition processes affecting the temporal evolution of the channel bed.

For constant - density debris flow, or fixed channel bed models, various rheological laws have been proposed. These include: the quadratic shear stress model [35], Bingham type approach [30] and the Herschel Bulkely model [17].

Because a debris flow, essentially, constitutes a multiphase system, any attempt at modelling this phenomenon that assumes, as a simplified hypothesis, homogeneous mass and constant density, conceals the interactions between the phases and prevents the possibility of investigating further mechanisms such as the effect of sediment separation (grading).

Modelling the fluid as a two - phase mixture overcomes most of the limitations mentioned above and

Paper received 04.05.2007; accepted 21.12.2007

Prof. Stefano Mambretti, Associate Professor, DIIAR - Politecnico di Milano, Italy; Prof. Daniele De Wrachien, Full Professor, Department of Agricoltural Hydraulics, State University of Milano, Italy; Prof. EnRICo Larcan, Full Professor, DIIAR - Politecnico di Milano, Italy. allows for a wider choice of rheological models.

Notwithstanding all these efforts, some phenomenological aspects of debris flow have not been understood yet, and something new has to be added to the description of the process to reach a better assessment of the events. In this contest, the mechanism of dam break wave should be further investigated. So far, this aspect has been analysed by means of the single phase propagation theory for clear water, introducing in the De Saint Venant (SV) equations a dissipation term to consider fluid rheology [16], [19].

Many other models, the so - called quasi - two phase - models use SV equations, together with erosion / deposition and mass conservation equations for the solid phase, and take into account mixture of varying concentrations. All these models feature monotonic velocity profiles that, generally, do not agree with experimental and field data.

In this paper a 1D two - phase model for debris flow propagation is proposed. SV equations, modified for including erosion / deposition processes along the mixture path, are used for expressing conservation of mass and momentum for the two phases of the mixture. The scheme is validated for dam - break problems comparing numerical results with experimental data. Comparisons are made between both wave depths and front propagation velocities obtained respectively on the basis of laboratory tests and with predictions from the numerical model proposed by McCormack - Jameson [34], [29]. These comparisons allow the assessment of the model performance and suggest feasible development of the research.

\section{Theoretical Approach}

Debris flow resulting from a sudden collapse of a dam (dam - break) are often characterised by the formation of shock waves caused by many factors such as valley contractions, irregular bed slope and non - zero tailwater depth. It is commonly accepted that a mathematical description of these phenomena can be accomplished by means of 1D SV equations [8], [7], [5].

Numerical treatments of such equations, generally, 
require schemes capable of preserving discontinuities, possibly without any special shift (shock - capturing schemes). Most numerical approaches have been developed in the last two or three decades, that include the use of finite differences, finite elements or discrete / distint element methods [3], [36].

The McCormack predictor - corrector explicit scheme is widely used for solving dam - break problems, due to the fact that it is a shock - capturing technique, with second order accuracy both in time and in space, and that the artificial dissipation terms, the so - called Total Variation Diminishing (TVD) Jameson correction, can be introduced, in order to avoid non - physical shocks and oscillations around discontinuities [20], [21].

The main disadvantage of this solver regards the restriction to the time step size in order to satisfy Courant - Friedrichs - Lewy (CFL) stability condition. However, this is not a real problem for dam break debris flow phenomena that require short time step to describe the evolution of the discharge.

\subsection{Governing Equations}

The 1D approach for unsteady debris flow triggered by dam - break is governed by the SV equations. This set of partial differential equations describes a system of hyperbolic conservation laws with source term $(\mathbf{S})$ and can be written in compact vector form:

$$
\frac{\partial \mathbf{V}}{\partial t}+\frac{\partial \mathbf{F}}{\partial s}=\mathbf{S}
$$

where:

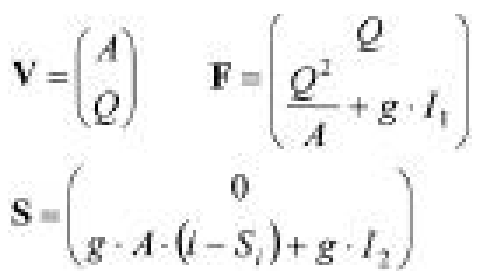

with $A(s, t)$ : wetted cross - sectional area; $Q(s, t)$ : flow rate; $s$ : spatial coordinate; $t$ : temporal coordinate; $g$ : acceleration due to gravity; $i$ : bed slope; $S_{i}$ : bed resistance term or friction slope, that can be modelled using different rheological laws [36].

The pressure force integrals $I_{1}$ and $I_{2}$ are calculated in accordance with the geometrical properties of the channel. $I_{1}$ represents a hydrostatic pressure form term and $I_{2}$ represents the pressure forces due to the longitudinal width variation, expressed as:

$$
\begin{aligned}
& I_{1}=\int_{0}^{\hbar}(H-\eta) \sigma(s, \eta) \cdot d \eta \\
& I_{2}=\int_{0}^{\hbar}(H-\eta) \cdot \frac{\partial \sigma}{\partial s} \cdot d \eta
\end{aligned}
$$

where $H$ : water depth; $\eta$ : integration variable indicating distance from the channel bottom; $\sigma(s, \eta)$ : channel width at distance $\eta$ from the channel bed, expressed as:

$$
\sigma(s, \eta)=\frac{\partial A(s, \eta)}{\partial \eta}
$$

To take into account erosion / deposition processes along the debris flow propagation path, which are directly related to both the variation of the mixture density and the temporal evolution of the channel bed, a mass conservation equation for the solid phase and a erosion / deposition model have been introduced in the SV approach.

Defining the sediment discharge as:

$$
q(s, t)=E \cdot B
$$

with $E$ : erosion / deposition rate; $B$ : wetted bed width, the modified vector form of the SV equations can be expressed according to eq. (1), where:

$$
\begin{aligned}
& \mathbf{V}=\left(\begin{array}{c}
A \\
Q \\
c_{x} \cdot A
\end{array}\right) \quad \mathbf{F}=\left(\begin{array}{c}
Q \\
\frac{Q^{2}}{A}+g \cdot l_{1} \\
c_{x} \cdot Q
\end{array}\right) \\
& \mathbf{S}=\left(\begin{array}{c}
q(s, t) \\
g \cdot A\left(i-S_{i}\right)+g \cdot I_{2} \\
E \cdot c_{x} \cdot B
\end{array}\right)
\end{aligned}
$$

with $c_{s}$ : volumetric solid concentration in the mixture; $c_{*}$ : bed volumetric solid concentration.

\subsection{Two Phase Mathematical Model}

Debris flow is, essentially, a multiphase system, so modelling the flow as a two - phase mixture is the best way to predict these phenomena. The change in debris flow density can be modelled through mass and momentum balance of both phases (solid and liquid) and interactions between the two could be assessed by means of appropriate additional terms [46], [48].

The erosion/deposition rate is, generally, controlled by the excess of the local instantaneous concentration over the equilibrium concentration. Egashira and Ashida [18] and Honda and Egashira [28] computed this rate by means of a simple relationship, while Takahashi et al. [45] proposed semi - empirical expressions. All these models ignore the spatial and temporal variations of debris flow density in the momentum balance equations.

In the present work granular and liquid phases are considered. The model includes two mass and momentum balance equations for both the liquid and solid phases respectively. The interaction between phases is simulated according to Wan and Wang hypothesis [47]. The system is completed with equations to estimate erosion/deposition rate derived from the Egashira and Ashida relationship and by the assumption of the Mohr - Coulomb failure criterion for non cohesive materials.

\subsection{Mass and momentum equations for the liquid phase}

Mass and momentum equations for water can be expressed in conservative form as: 


$$
\begin{aligned}
& \frac{\partial Q_{i}(s, t)}{\partial s}+\frac{\partial\left(c_{l} \cdot A(s, t)\right)}{\partial t}=0 \\
& \frac{\partial Q_{i}}{\partial t}+\frac{\partial}{\partial s}\left(\beta \cdot \frac{Q_{l}^{2}}{c_{l} \cdot A}\right)= \\
& \quad=g \cdot c_{l} \cdot A \cdot\left(i-J-\frac{\partial H}{\partial s}\right)-F
\end{aligned}
$$

with $Q_{l}(s, t)$ : flow discharge; $c_{l}$ : volumetric concentration of water in the mixture; $\beta$ : momentum correction coefficient that we will assume to take the value $\beta=1$ from now on; $J$ : slope of the energy line according to Chézy's formula; $i$ : bed slope; $F$ : friction force between the two phases.

According to Wan and Wang [47], the interaction of the phases at single granule level $f$ is given by:

$$
f=c_{D} \cdot \frac{\pi-d_{90}^{2}}{4} \cdot \frac{\rho_{f} \cdot\left(v_{f}-v_{3}\right)}{2} \cdot\left|v_{l}-v_{t}\right|
$$

with $c_{D}$ : drag coefficient; $v_{l}$ : velocity of water; $v_{s}$ : velocity of the solid phase; $d_{50}$ : mean diameter of the coarse particle; $\rho_{l}$ : liquid density.

Assuming grains of spherical shape and defining the control volume of the mixture as:

$$
V_{c}=B \cdot H \cdot \cos \vartheta \cdot d s \approx B \cdot H \cdot d s
$$

with $\vartheta$ channel slope angle, which holds for low channel slopes, the whole friction force $F$ between the two phases for the control volume can be written as:

$$
F=\frac{3}{4} \cdot c_{D} \cdot \rho_{l} \cdot\left(v_{l}-v_{2}\right) \cdot\left|v_{l}-v_{s}\right| \cdot \frac{c_{s}}{d_{30}} \cdot H \cdot B \cdot d s
$$

\subsection{Mass and momentum equations for the solid phase}

Mass and momentum conservation equations for the solid phase of the mixture can be expressed as:

$$
\begin{aligned}
& \frac{\partial\left(c_{s} \cdot A\right)}{\partial t}+\frac{\partial Q_{s}}{\partial s}=E \cdot c_{*} \cdot B \\
& \frac{\partial Q_{i}}{\partial t}+\frac{\partial}{\partial s}\left(\beta \cdot \frac{Q_{s}^{2}}{c_{s} \cdot A}\right)= \\
& \quad-g \cdot \frac{\rho_{1}-\rho_{l}}{\rho_{s}} \cdot c_{s} \cdot\left(1+i^{2}\right) \cdot \frac{\partial H}{\partial s} \cdot A+F+ \\
& \quad+g \cdot \frac{\rho_{s}-\rho_{i}}{\rho_{3}} \cdot c_{s} \cdot\left(i^{2}-1\right) \cdot \operatorname{tg} \delta \cdot A+ \\
& \quad+g \cdot \frac{\rho_{3}-\rho_{l}}{\rho_{3}} \cdot c_{s} \cdot A \cdot i
\end{aligned}
$$

with $Q_{s}(s, t)$ : discharge of the solid rate; $\rho_{s}$ : solid phase density.

According to Ghilardi et at. [22] and to Egashira and Ashida [18], the bed volumetric solid concentration $c_{*}$ was assumed to be constant and the erosion velocity rate $E$ a function of the mixture velocity $U$ :

$$
E=U \cdot k_{E} \cdot \operatorname{tg}\left(\vartheta_{f}-\vartheta_{e}\right)
$$

with $k_{E}$ : coefficient equal to 0.1 according to experimental data [18], [24], [22], [25].
This coefficient was not present in the original formula proposed by Egashira and Ashida, but was introduced by Ghilardi et al. in order to fit the experimental data carried out by Gregoretti.

Positive or negative values of $E$ correspond to granular material erosion or deposition, respectively. $\vartheta_{f}$ and $\vartheta_{e}$ represent the energy line and the bed equilibrium angles, respectively, expressed as [10]:

$$
\begin{aligned}
& \vartheta_{f}=\operatorname{arctg}\left[\frac{J}{\cos \theta}\right] \\
& \vartheta_{c}=\operatorname{arctg}\left[\frac{c_{s} \cdot\left(\rho_{s}-\rho\right)}{c_{s} \cdot\left(\rho_{s}-\rho\right)+\rho} \cdot \operatorname{tg} \phi\right]
\end{aligned}
$$

where the debris flow density is defined as:

$$
\rho=\left(\rho_{s}-\rho_{l}\right) \cdot c_{s}+\rho_{l}
$$

and $\phi$ is the static internal friction angle.

The equilibrium angle is a relevant parameter that depends, mainly, on the concentration of the mixture and on the ratio between solid and water density. When the slope of the channel bed has reached the equilibrium angle, no erosion or deposition occurs and a steady bottom state is reached.

Ghilardi's hypotheses refer to a set of equations that include two mass conservation equations (one for the mixture and another for the solid phase) and a single momentum balance equation for the 1D flow. This leads to the assumption that the finer solid fraction in the interstitial fluid is negligible. So, the same velocity for the coarser solid fraction is assumed too. In our two - phase model $U$ is defined as follows:

$$
U=c_{s} v_{s}+c_{l} v_{l}
$$

For $J$ several resistance formulas have been implemented, from the dispersive stress model proposed for stony debris flow by Takahashi [42] to the traditional Manning formula [14]. In the present work the Takahashi equation has been chosen, according to the dilatant fluid hypothesis developed by Bagnold [6]:

$$
\frac{U^{2}}{\left(\frac{2}{5 \cdot d_{90}} \cdot \frac{H}{\lambda}\right)^{2} \cdot \frac{1}{a_{s} \cdot \operatorname{sen} \delta} \cdot\left[c_{s}+\left(1-c_{s}\right) \cdot \frac{\rho_{i}}{\rho_{s}}\right] \cdot g \cdot R}
$$

with $S_{i}$ : friction term and $R$ : hydraulic radius given by:

$$
R=\frac{A}{P}
$$

where $P$ is the wetted perimeter.

The quantity $\lambda$ (linear concentration) depends on the granulometry of the solids in the form:

$$
z=\frac{c_{2}^{113}}{c_{*}^{113}-c_{2}^{113}}
$$

where $c_{m}$ : maximum packing volume fraction (for perfect spheres $\left.c_{m}=0.74\right) ; a_{b}$ : empirical constant.

Takahashi fitted his experimental data in flumes 
with fixed walls using for $a_{b}$ the value given by Bagnold $a_{b}=0.042$. In presence of an erodible granular bed, he found higher resistance, so the value of $a_{b}$ was incremented to $0.35-0.50$. The dynamic internal angle of friction $\delta$ was assessed by reducing the static one $\phi$ of $3^{\circ}-4^{\circ}$ [42].

For high values of sediment concentration, the resistance is mainly caused by the dispersive stress and the roughness of the bed does not influence the resistance [39]. For low values of the same characteristic the energy dissipation is mainly due to turbulence in the interstitial fluid and the influence of the wall roughness become important. In such case, Takahashi [42] suggests to use the Manning's equation or similar resistance law.

With regard to the momentum conservation equation (12) all its terms have been evaluated considering only the fraction of volume actually occupied by grains and ignoring the erosion / deposition velocity.

The weight of the solid phase in the control volume can be expressed as:

$$
\begin{aligned}
W^{\prime}= & W_{s}-S_{4}= \\
& g \cdot\left(\rho_{3}-\rho_{l}\right) \cdot c_{s} \cdot B \cdot B \cos \theta \cdot d s= \\
& g \cdot\left(\rho_{3}-\rho_{l}\right) \cdot c_{s} \cdot B \cdot H \cdot d s
\end{aligned}
$$

where $S_{A}$ represents the buoyancy force.

Considering the control volume to be in critical equilibrium conditions and assuming an hydrostatic distribution of solid phase pressure, the Mohr Coulomb failure criterion for non cohesive materials allows to assess the bottom shear stress of the volume:

$$
T=\tau_{\operatorname{lin}} \cdot B=\sigma_{n}^{\prime} \cdot \operatorname{tg} \phi \cdot B
$$

where $\tau_{\lim }$ is the shear stress in limit equilibrium conditions and $\sigma_{n}^{\prime}$ the normal stress for the solid phase along the failure surface, which can be expressed as:

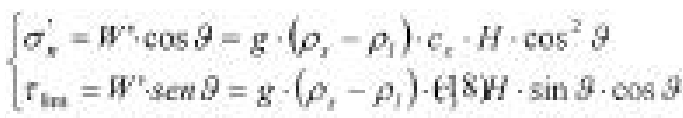

When the stress condition along the failure surface is known, it is possible to evaluate the lateral stress, and so the lateral forces $\Pi_{1}$ and $\Pi_{2}$ of the control volume.

For mild bed slopes, the dynamic internal angle $\delta$ and the static one $\phi$ are equal in critical equilibrium conditions, so the shear stress $\tau_{\text {lim }}$ can be written as:

$$
t_{1 i n}=-g \cdot\left(\rho,-\rho_{i}\right) \cdot c_{,}+H \cos g \cdot \sin g
$$

Finally, the difference between lateral forces $\Pi$ and $\Pi_{2}$ and the bottom shear stress $\tau_{\lim }$ of the control volume become:

$$
\begin{aligned}
& \Pi_{1}-\Pi_{2}=-\frac{\partial \Pi_{1}}{\partial s} \cdot d s- \\
& -g \cdot\left(\rho_{a}-\rho_{l}\right) \cdot c_{s} \cdot\left(1+i^{2}\right) \cdot \frac{\partial H}{\partial s} \cdot A \cdot d s \\
& T_{\text {la }}=\sigma^{\prime} \cdot \operatorname{tg} \phi \cdot B= \\
& g \cdot\left(\rho_{s}-\rho_{t}\right) \cdot c_{s} \cdot\left(1-i^{2}\right) \cdot \operatorname{tg} \phi \cdot A \cdot d s
\end{aligned}
$$

It is worth mentioning that the momentum equation (12) holds when both phases of the mixture coexist. When a single momentum balance equation of the debris flow is considered, both the friction between the two phases and the buoyancy forces vanish.

\subsection{Numerical Model}

The SV equations for 1D two - phase unsteady debris flow can be expressed in compact vector form as follows:

$$
\frac{\partial \mathbf{V}}{\partial \partial}+\frac{\partial \mathbf{F}^{\prime}}{\partial s}+\mathrm{C} \cdot \frac{\partial \mathbf{F}^{\prime \prime}}{\partial s}=\mathbf{S}
$$

where, for a rectangular section channel and for a completely mixed fluid,

$$
\begin{aligned}
& \mathrm{V}=\left(\begin{array}{c}
c_{i} \cdot A \\
c_{s} \cdot A \\
Q_{i} \\
Q_{3}
\end{array}\right) \quad \mathbf{F}=\left(\begin{array}{c}
Q_{i} \\
Q_{s} \\
\frac{Q_{i}^{2}}{c_{l} \cdot A} \\
\frac{Q_{i}^{2}}{c_{i} \cdot A}
\end{array}\right) \\
& \mathbf{F}^{\prime \prime}=\left(\begin{array}{c}
0 \\
0 \\
\frac{1}{2} \cdot g \cdot \frac{A^{2}}{B} \\
\frac{1}{2} \cdot g \cdot \frac{\rho_{i}-\rho_{i}}{\rho_{i}} \cdot\left(1+i^{2}\right) \cdot \frac{A^{2}}{B}
\end{array}\right)
\end{aligned}
$$

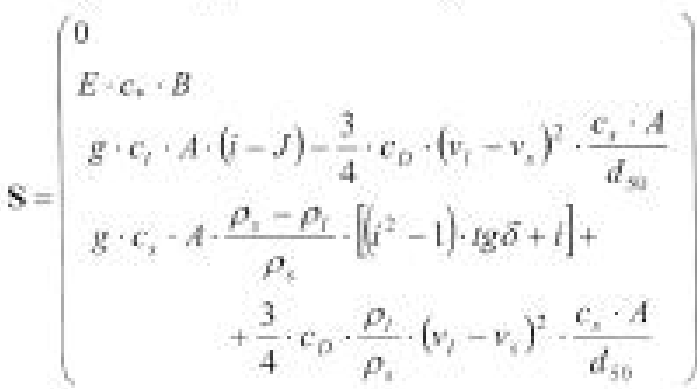

$$
\begin{aligned}
& \mathbf{C}=\left(\begin{array}{llll}
0 & \theta & c_{1} & c_{s}
\end{array}\right)
\end{aligned}
$$

\subsection{Mc Cormack - Jameson Solver}

Numerical solution of equation (27) is based on the well known McCormack - Jameson predictor - corrector finite difference scheme [34], [29].

$$
\begin{aligned}
& \mathbf{V}_{i}^{\prime \prime}=\mathrm{V}_{i}^{\prime}-\frac{\Delta z}{\Delta v}\left[(1-\theta) \mathbf{F}_{i+2}^{\prime \prime}-(1-2 \theta) \mathrm{F}_{i}^{\prime \prime}-\boldsymbol{F}_{i-1}^{\prime a}\right]+
\end{aligned}
$$

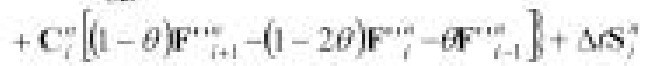

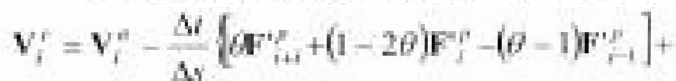

$$
\begin{aligned}
& +\mathbf{C}_{i}^{p}\left[\boldsymbol{F}_{i+1}^{-1 p}+(1-2 \theta) \mathbf{F}^{\prime \prime}+(\theta-1) \mathbf{F}^{n+}+1\right]+\Delta \mathbf{S}^{\prime \prime} \\
& \mathbf{V}_{i}^{A+1}=\frac{1}{2}\left(\mathbf{V}_{i}^{p}+\mathbf{V}_{i}^{r}\right)
\end{aligned}
$$

where $i$ and $n$ are the spatial and temporal grid levels, $\Delta s$ and $\Delta t$ the spatial and temporal steps, with $s_{i}=(1-$ 
i) $\Delta s, \quad t=(1-n) \Delta t, \quad i, n=1,2 \ldots$ and the superscripts " $p$ " and " $c$ " indicate the variable at predictor and corrector steps, respectively.

The order of backward and forward differentiation in the scheme is ruled by $\theta$ which can be also cyclically changed during the computations [11]. In our scheme $\theta$ is set equal to 1 , to obtain a best stability condition.

Artificial additional terms must be added to the original form of the McCormack scheme, in order to avoid spurious oscillations and discontinuities without any physical significance. Different approaches have been proposed to eliminate these effects [37], [29], [26], [11]. All these approaches allow to avoid no physical shock in numerical solutions and to achieve suitable results.

Verification of shock capturing numerical schemes is often performed comparing computed results with experimental data in which shocks are not present at all. In the present work, the artificial dissipation terms introduced by Jameson [29], according to the classical theory developed in the field of aerodynamics, are assumed.

In order to solve the problem of propagation of a debris flow wave resulting from the break of a storage dam, appropriate initial, boundary and stability conditions have to be introduced.

\subsection{Initial and boundary conditions}

Initial conditions are discontinuous across the dam location. As a matter of fact, it is assumed that at time $t=0$, there exists no flow at all, i.e. the mixture behind the dam is still and the downstream bed is dry. This lead to an unrealistic stationary shock, if the McCormack original scheme, without artificial dissipation terms, is adopted [1]. The addition of the dissipation terms allows to remove this unrealistic shock and to avoid any approximate procedure [8].

Regarding the boundary conditions, to evaluate predictor step at the node $(i, n+1)$, the variable values at the grid points $(i-1, n),(i, n)$ and $(i+1, n)$ must be known. This implies that to properly apply the McCormack solver at the boundary node of the upstream solid wall, when the depth of the mixture is not zero at the upstream end of the reservoir, appropriate symmetric conditions for depth and volumetric concentrations, and anti - symmetric conditions for velocities should be defined.

No problem arises for the assessment of the correct step, due to the fact that every computation code refers to grid points inside the domain. It is worth underlying that the McCormack scheme has a strong shock - capturing capability. Thus, it can be used for the solution of the unsteady flow equations, in conservative law form, either when the flow is wholly gradually varied or the latter is affected with surges or shocks. This is the case of a dam - break flow advancing down a river with an initial flow, and it constitutes the so - called wet - bed dam - break problem [8].

\subsection{Stability conditions}

In order to satisfy the numerical stability requirements, the time step has to abide by the Courant Friedrichs - Lewy (CFL) criterion [15], [41], which is a necessary but not sufficient condition:

$$
\Delta t=C_{N} \cdot \frac{\Delta x}{\max |U|+c]}
$$

where $c$ : celerity of a small flow disturbance, defined by:

$$
c=\sqrt{g \cdot \frac{A}{B}}
$$

and $C_{R}$ : Courant number.

For a fixed spatial grid, the minimum value of $\Delta t$ satisfying Eq. 29 is determined at the end of the computation for a given time step. This value is then used as the time increment for the computation during the next step. In this way the largest possible time increment can be utilized at each time step. This process required the calibration of three coefficients: the drag coefficient $C_{D}$ and the two Jameson parameters of artificial viscosity $\alpha^{(2)}$ and $\alpha^{(4)}$. Their values are: $C_{D}=0.2 ; \alpha^{(2)}=0.5, \alpha^{(4)}=0.2$.

The Jameson parameters have been calibrated by Aureli et al. [4] and checked by experiments in clear water in our Laboratory.

About the drag coefficient $C_{D}$, it is widely accepted that it ranges between 0.1 and 0.6 for a sphere in turbulent flow. In this work values of $0.2,0.4$ and 0.6 have been tried in the model, and the value of 0.2 was found the most suitable to fit the experimental data.

In the developed code a fixed and very small value of $\_t$ has been set at the beginning of the simulations, verifying during the run that the CFL condition was assured, being always the Courant number $C_{R}<0.8$.

\section{Experimental Results and Test Conditions}

To validate the model, comparisons have been made between its predictions and experimental results carried out in the Hydraulic Laboratory of the Politecnico di Milano. The tests were performed with flows of water and homogeneous granular mixtures in a uniform geometry flume reproducing dam- break waves [32], [33]. The experimental set - up consisted of a loading tank (dimensions $0.5 \mathrm{~m}$ x $0.5 \mathrm{~m}$ x $0.9 \mathrm{~m}$ ) with a downstream wall made of sluice gate, a pneumatic control device and a very short opening time $(0.3 \mathrm{~s})$ (Figure 1).

The mixture flowed in a $6 \mathrm{~m}$ long channel of square section $(0.5 \mathrm{~m} \times 0.5 \mathrm{~m})$ and adjustable slope. To enable camera recordings, one of the flume lateral walls contained glass windows.

Experimental tests were performed by changing the channel slope, the bottom roughness (smooth bottom made of galvanised plate or rough bottom covered with an homogeneous layer of gravel, with $d_{50}=$ $0.005 \mathrm{~m}$ ), the solid material characteristics (vedril: 
$\rho=1168 \mathrm{~kg} / \mathrm{m}^{3}, d_{50}=0.003 \mathrm{~m}$; or gravel: $\rho=2621$ $\left.\mathrm{kg} / \mathrm{m}^{3}, d_{50}=0.005 \mathrm{~m}\right)$ and the volumetric concentration of the mixture.

Recordings were made with a Sony Digital Handcam, model DCR - TRV32 E camera, which had an acquisition velocity of 25 frames per second, and were electronically elaborated. Table 1 reports the full list of the experimental tests performed. Each run was repeated three times to allow debris flow recordings along three adjacent windows [9]. In the tests, all parts of each run, which allowed a clear reading of the mixture's behaviour in its different phases, were used. As a consequence, the same run could be used to assess front, body or end of the wave characteristics.

\section{Comparisons Between Model Prediction and Experimental Results}

As mentioned, the experiments consisted of creating, in controlled conditions, dam - break wave of the mixtures, and measuring both the flow depth versus time at different points of the flume (1.40, 2.00, 3.20 and $4.80 \mathrm{~m}$ downstream of the gate) and the front wave velocities from the available recordings.

To take into account different behaviours of the flow, the experimental data have been compared with the predictions of three rheological laws included in the one phase model (called "Water", "Fix Bagnold" and "Mobile Bagnold") and with those of the two phase model.

\subsection{Wave depth comparison}

Comparisons between experimental and predicted depths are shown in Figures $2 \mathrm{a}-2 \mathrm{~d}$. These Figures

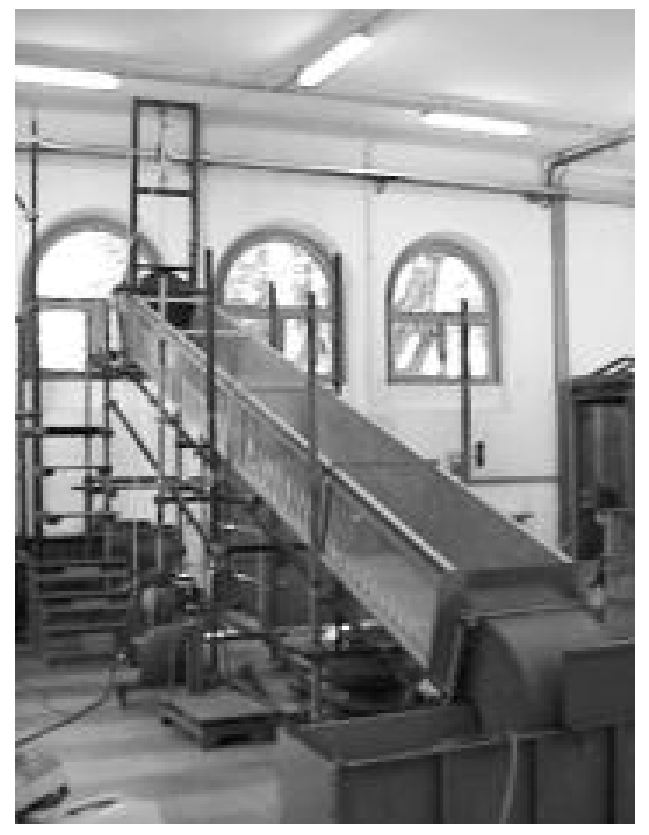

Fig. 1 - Experimental set - up.

regard only the tests performed with higher slope $\left(15^{\circ}\right.$ and $20^{\circ}$ ) where the complete mixing hypothesis seems more reliable. Conversely, for lower channel slopes and low velocities, immature debris flow are expected [33]. Takahashi [42] has suggested to distinguish mature and immature debris flow by means of a criterion based on the hypothesis of equality between the shear velocity and the settling velocities of the particles. This criterion, that requires the calibration of an empirical expression, is unsatisfactory, probably due to the fact that the data used for its calibration were taken in uniform or steady flow. Thus, Larcan et

\begin{tabular}{|c|c|c|c|c|}
\hline Channel slope & $\begin{array}{c}\text { Loading tank } \\
\text { bottom }\end{array}$ & Channel bottom & $\begin{array}{c}\text { Granular material } \\
\text { employed }\end{array}$ & $\begin{array}{c}\text { Concentration } \\
{[\%]} \\
\end{array}$ \\
\hline $3.2^{\circ}$ & Plane & Smooth & Vedril & $20,40,60$ \\
\hline \multirow{4}{*}{$5^{\circ}$} & \multirow{4}{*}{ Inclined } & \multirow{2}{*}{ Smooth } & Vedril & $20,40,60$ \\
\hline & & & Gravel & $20,40,60$ \\
\hline & & \multirow{2}{*}{ Rough } & Vedril & $20,40,60$ \\
\hline & & & Gravel & $20,40,60$ \\
\hline \multirow{4}{*}{$10^{\circ}$} & \multirow{4}{*}{ Inclined } & \multirow{2}{*}{ Smooth } & Vedril & $20,40,60$ \\
\hline & & & Gravel & $20,40,60$ \\
\hline & & \multirow{2}{*}{ Rough } & Vedril & $20,40,60$ \\
\hline & & & Gravel & 20 \\
\hline \multirow{5}{*}{$15^{\circ}$} & Plane & Smooth & Vedril & $20,40,60$ \\
\hline & \multirow{4}{*}{ Inclined } & \multirow{2}{*}{ Smooth } & Vedril & $20,40,60$ \\
\hline & & & Gravel & $20,40,60$ \\
\hline & & \multirow{2}{*}{ Rough } & Vedril & $20,40,60$ \\
\hline & & & Gravel & $20,40,60$ \\
\hline \multirow{4}{*}{$20^{\circ}$} & \multirow{4}{*}{ Inclined } & \multirow{2}{*}{ Smooth } & Vedril & $20,40,60$ \\
\hline & & & Gravel & $20,40,60$ \\
\hline & & \multirow{2}{*}{ Rough } & Vedril & $20,40,60$ \\
\hline & & & Gravel & 20,40 \\
\hline
\end{tabular}

TABLE 1 - Experimental runs list. 
al. [33] proposed a new criterion based on mixture velocity and concentration, which shows that in most real cases immature debris flow is unlikely to happen.

Comparisons show good agreement on the general shape that includes a steep front immediately followed by the maximum wave height and a decrease in flow depths down to an asymptotic value reached at the stoppage. It should be noted that the front does not tend to become diffuse and that the general behaviour of the numerical model seems to be consistent with the physical problem featured. Only in the tail of the wave, where the code usually underestimates the mixture depths, mainly in the tests performed with artificially roughened bottom, the model loses consistency. This must be related to the specific feature of the model that distributes the granular material uniformly through the wave, whilst in the experimental flume it is deposited in a non uniform way. Moreover, the erosion / deposition model has been developed under one phase assumption. In general terms, it should be underlined that, when the numerical model uses velocity and head loss values of the water in order to assess the erosion / deposition rate $E$, predictions are close to experimental results while, when the code adopts velocity and head loss values equal to an average between those of the two phases (liquid and solid) the results worsen. This behaviour does not prove that the model is unsuitable to describe dam - break phenomena of debris flow, but it shows that it could be difficult to predict precisely the area reached by a given debris flow even though velocities and wave depths are well represented during the fully developed flow phase.

\subsection{Front velocity comparison}

Table 2 shows a comparison between the velocities of the front of the wave measured by the recordings and the velocities predicted by the numerical model. It could be said that, except for few cases, the match is quite good and the agreement between computed and experimental results is very satisfactory.

According to Figures 2a-2d and to Table 2, each flow appears to be divided into a starting phase, a fully developed flow phase, and a stopping phase.

\begin{tabular}{|ccccc|}
\hline Slope & Conc. & $\begin{array}{c}\text { Exper. } \\
\text { velocity } \\
{[\mathrm{m} / \mathrm{s}]}\end{array}$ & $\begin{array}{c}\text { Model } \\
\text { velocity } \\
{[\mathrm{m} / \mathrm{s}]}\end{array}$ & $\begin{array}{c}\text { Error } \\
{[\%]}\end{array}$ \\
\hline \multirow{3}{*}{$15^{\circ}$} & $20 \%$ & 2.50 & 2.76 & 9.4 \\
& $40 \%$ & 2.50 & 2.59 & 3.5 \\
& $60 \%$ & 2.50 & 1.99 & -25.0 \\
$20^{\circ}$ & $20 \%$ & 3.33 & 3.00 & -11.0 \\
& $60 \%$ & 2.50 & 2.72 & 8.0 \\
& $60 \%$ & 2.14 & 2.33 & 8.0 \\
\hline
\end{tabular}

TABLE 2 - Comparison between measured and predicted velocities.

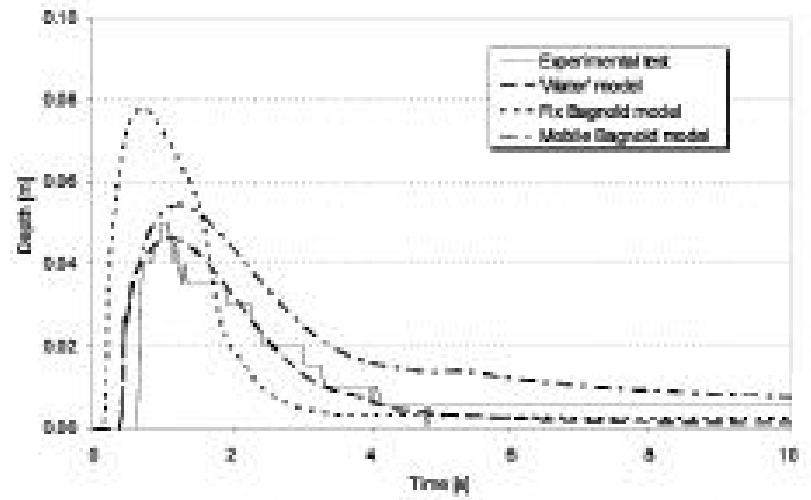

2a - Water-gravel, ahs 200 , conc. $40 \%$, slope $15^{\circ}$, smooth bottom

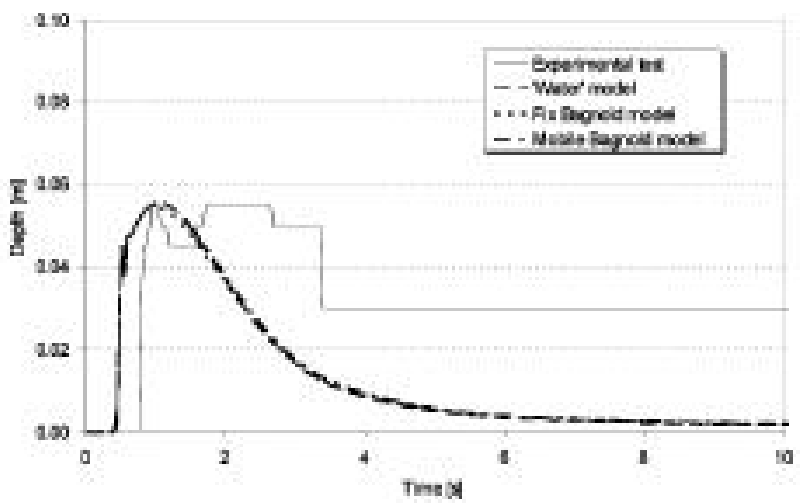

$2 b$ - Water-gravel, abs 200 , conc. $40 \%$, slope $20^{\circ}$, rough bottoen

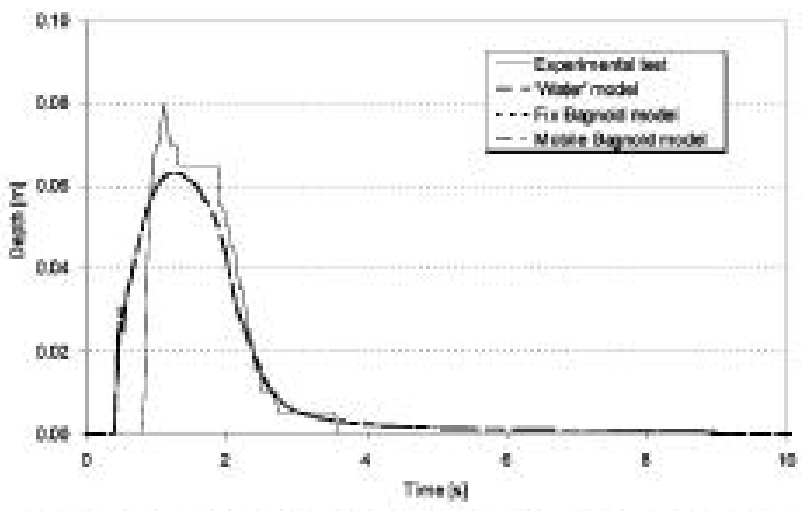

$2 e$ - Water-vedril, abs 200, conc. $40 \%$, slope $15^{\circ}$, smooth bottom

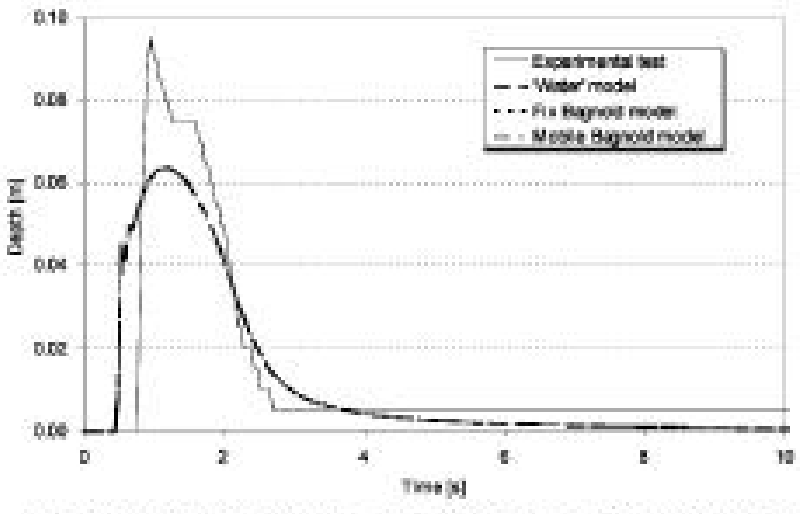

$2 \mathrm{~d}$ - Water-vetril, abs 200 , conc, $40 \%$ slope $20^{\circ}$, rough botiom

Fig. 2 - Debris flow wave in some characteristic sections of the experimental channel. Comparison between mathematical model and experimental results. 
The initial situation could be described as a static condition - all velocities equal to zero being the opening of the gate followed by the occurrence of a velocity affecting progressively all the length of the flume.

At the same time, the maximum wave depth decreases under the effort of gravity. The main features of the fully developed flow phase are a slow decrease of the maximum flow depth and a constant velocity for the front propagation, the latter being valid during the whole starting and fully developed flow phases. The stopping phase is characterised by a fast decrease of both maximum flow depth and front velocity down to zero. This behaviour, that features a theoretical dam - break problem determined by a shock wave, is satisfactorily described by the numerical model.

\subsection{Comparison between different models}

To further assess the capability of the model proposed to reproduce debris flow phenomena, comparisons have been made between experimental results and those predicted by three models: one - phase, quasi two - phase and fully two - phase model (Figures $3 a-3 b)$. The Figures point out clearly that the two - phase model provides a better approximation of the laboratory data, both in the peak and in the depth of deposited material data.

Moreover, the model proposed can easily be extended to channels with arbitrary cross sections, for debris flow routing, as well as for solving different

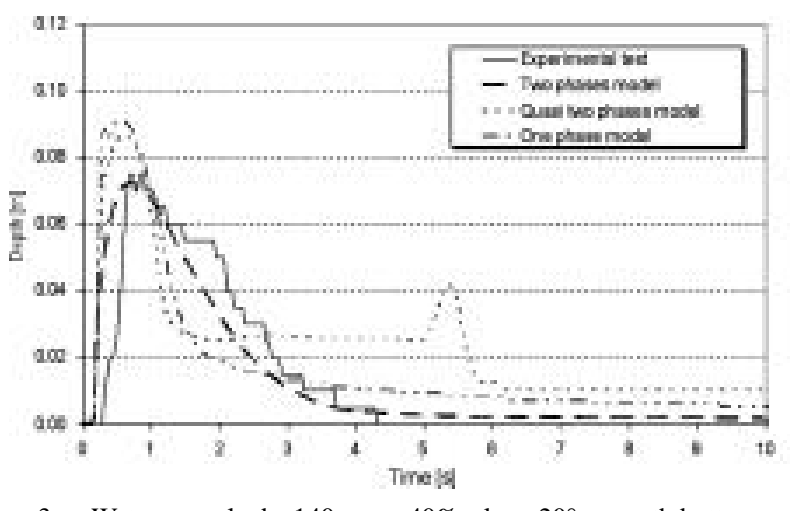

3a - Water-gravel, abs 140 , conc. $40 \%$, slope $20^{\circ}$, smooth bottom

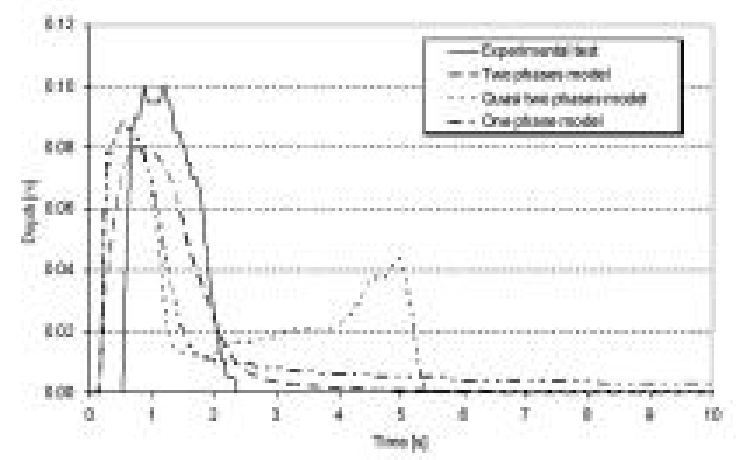

$3 b$ - Water-vedril, abs 480 , conc. $40 \%$, slope $20^{\circ}$, smooth bottom

Fig. 3 - Comparison of the results of one-phase, quasi-two-phase and two-phase models with experimental ones. problems of unsteady flow in open channels by incorporating the appropriate initial and boundary conditions. The great advantages of the technique developed are based on the strong shock - capturing ability of the McCormack - Jameson numerical scheme, as well as on the simplicity of application of the resulting algorithm when considering $1 \mathrm{D}$ debris flow problems.

\section{Conclusions}

Achieving a set of debris flow constitutive equations is a task which has been given particular attention by the scientific community during the second half of the last century.

In this context, the present paper describes the main features and characteristics of a numerical model suitable to solve the SV equations, modified for including two - phase debris flow phenomena, and able to assess the depth of the wave and the velocities of both the liquid and solid phases of no - stratified (mature) flow, following dam - break events.

The model is based on mass and momentum conservation equations for both liquid and solid phases. The McCormack - Jameson two - step explicit scheme with second order accuracy was employed for the solution of the equations, written in a conservative - law form. The technique was applied for determining both the propagation and the profile of a debris flow wave resulting from the instantaneous and complete collapse of a storage dam. The actual initial and boundary conditions for the problem considered, i.e. a zero flow depth at the leading front of the wave, were used in the application of the numerical technique. Different experimental cases of dam - break situations in a square section channel were considered for the purpose of comparing results.

Agreements between computational and experimental results regarding both wave front - advance and stage hydrographs are considered very satisfactory.

In order to describe stratified (immature) flow, it is necessary to widen the reach of the model and to take into account mass and momentum conservation equations for each phase and layer. Momentum conservation equations describe energy exchanges between the two phases in the same layer and between layers, while mass conservation equation describe mass exchange between layers. This improvement will allow a better description of both the tail of the wave and the experiments carried out with lower flume inclinations, which are immature and, therefore, cannot be simulated with the model herewith presented.

Within this ground, in order to analyse reverse grading (sorting) it is necessary to analyse the wave propagation process, when the solid phase is composed of no - homogeneous material. In this case the model should be improved in order to feature the distribution of the material of different size of the solid phase: larger size material positioned in the front and 
in the top of the wave, and finer one in the bottom and in the tail.

\section{References}

[1] Alcrudo F., Garcia Navarro P., Computing two dimensional flood propagation with a high resolution extension of McCormack's method Proc. of International Conference on Modelling of Flooding Propagation over Initially Dry Areas, Milan, 1994.

[2] Armanini A., Fraccarollo L., Critical conditions for debris flow in Debris Flow Hazard Mitigation: Mechanics, Prediction and Assessment, Eds. Chen, New York, 1997, 434-443.

[3] Asmar B.N., Lanston P.A., ERgenzinger Z., The potential of the discrete method to simulate debris flow Proceeding of the First International Conference on Debris Flow Hazard Mitigation: Mechanics, Prediction and Assessment, Eds. Chen, New York, 1997

[4] Aureli F., Maione U., Mignosa P., Tomirotti M., Fenomeni di moto vario conseguenti al crollo di opere di ritenuta, parte I: modellazione numerica e confronto con dati sperimentali di letteratura, L'Acqua n. 4, 1998 (in Italian).

[5] Aureli F., Mignosa P., Tomirotti M., Numerical simulation and experimental verification of dam break flow with shocks Journal of Hydraulic Research, 2000, 38, 197-216.

[6] BAGNOLD R.A., Experiments on a gravity - free dispersion of large solid spheres in a Newtonian fluid under shear in Proceedings of the Royal Society of London, Series A, 225, 1954, 49-63.

[7] Bechteler W., Kulisch H., NuJIC M., 2D dam break flooding wave: comparison between experimental and calculated results Floods and Flood Management, Ed. Saul, Dodrecht, 1992.

[8] Bellos V., SAKKaS J.G., 1D dam - break flood propagation on dry bed Journal of Hydraulic Engineering, 1987, ASCE 113(12), 1510-1524.

[9] Bertalli L., Larcan E., Mambretti S., Leggi di resistenza al moto nelle colate di detriti conseguenti al crollo di dighe. 2. Modello numerico e confronti con $i$ risultati sperimentali. Proceedings $28^{\circ}$ Convegno di Idraulica e Costruzioni Idrauliche, Potenza, 16 - 19 settembre 2002 (in Italian).

[10] Brufau P., Garcia - Navarro P., Ghilardi P., NaTALE L., SAVI F., ID Mathematical modelling of debris flow Journal of Hydraulic Research, 38, 2001, 435-446.

[11] Chaudry M.H., Open - Channel Flow, New Jersey, 1993

[12] CHEN L.C., Generalized viscoplastic modelling of debris flow Journal of Hydraulic Engineering, 1988, 114, 237-258.

[13] CHEN C.L., Ling C.H., Resistance formulas in hydraulics based models for routing debris flow in Debris Flow Hazard Mitigation: Mechanics, Prediction and Assessment, Eds. Chen, New York, 1997, 360372.

[14] CHOw V.T., Open Channel Hydraulics McGraw Hill, 1959.

[15] Courant R., Friedrichs K.O., Lewy H., On the partial differential equation of mathematical physics IBM Journal, 11, 1967, 215-234.
[16] Coussot P., Steady, laminar, flow of concentrated mud suspensions in open channel, Journal of Hydraulic Research, Vol. 32 n. 4, 535-559, 1994.

[17] Coussot P., Mudflow rheology and dynamics Rotterdam, 1997.

[18] Egashira S., Ashida K., Sediment transport in steep slope flumes, Proc. of RoC Japan Joint Seminar on Water Resources, 1987.

[19] FREAD D.L., JIN M., One-dimensional Routing of Mud/Debris flows using NWS FLDWAV Model, Proc. of First International Conference on Debris Flow Hazards Mitigation: Mechanics, Prediction and Assessment, San Francisco, California, 7-9 August 1997.

[20] Garcia R., KaHAWITA R.A., Numerical solution of the De Saint Venant equations with the McCormack finite - difference scheme International Journal of Numerical Methods in Fluids, 1986, 6, 259-274.

[21] Garcia Navarro P., SaViròn J.M., McCormack methods for numerical simulation of $1 D$ discontinuous unsteady open channel flow Journal of Hydraulic Research, 1992, 30(1), 313-327.

[22] Ghilardi P., Natale L., Savi F., Two mathematical models simulating a real-world debris-flow, Proc.IAHR Symposium on River, Coastal and Estuarine Morphodynamics, Genova, 1999.

[23] Ghilardi P., Natale L., Savi F., Debris flow propagation and deposition on urbanized alluvial fans, $\mathrm{Ex}$ cerpta, 14, 2000, 7-20.

[24] Gregoretti C., Fronte di debris-flow. Composizione e celerità, L'acqua n. 6, 29-39, 1998 (in Italian).

[25] Gregoretti C., Stima della velocità massima del fronte di una colata detritica che si propaga in un alveo torrentizio, Idra 2000 (in Italian).

[26] HARTEn A., High resolution schemes for hyperbolic conservation laws Journal of Computational Physics, 49, 1983, 357-394.

[27] Hirano M., Hasada T., Banihabib M.E., Kawahasa K., Estimation of hazard area due to debris flow in Debris Flow Hazard Mitigation: Mechanics, Prediction and Assessment, Eds. Chen, New York, 1997, 697-706.

[28] Honda N., Egashira S., Prediction of debris flow characteristics in mountain torrents in Debris Flow Hazard Mitigation: Mechanics, Prediction and Assessment, Eds. Chen, New York, 1997, 707-716.

[29] JAMESON A., Transonic airfoil calculation using the Euler equations Numerical Models in Aeronautical Fluid Dynamics, Ed. P.L. Roe, 1982, Academic Press, New York.

[30] JAN C.D., A study on the numerical modelling of debris flow in Debris Flow Hazard Mitigation: Mechanics, Prediction and Assessment, Eds. Chen, New York, 1997, 717-726.

[31] Julien P.Y., O’Brien J.S., Physical properties and mechanics of hyperconcentrated sediment flows, Proc. Spec. Conference on Delineation of Landslides, Flash Flood and Debris Flow Utah, USA, 1985, 260279.

[32] Larcan E., Mambretti S., Orsi E., Leggi di resistenza al moto nelle colate di detriti conseguenti al crollo di dighe. 1. Apparato sperimentale e primi risultati. Proceedings of $28^{\circ}$ Convegno di Idraulica e Costruzioni Idrauliche, Potenza, 16 - 19 settembre 2002 (in Italian).

[33] Larcan E., Mambretti S., Pulecchi M., A procedure for the evaluation of debris flow stratification. 
Proc. of the $1^{\text {st }}$ International Conference on Monitoring, Simulation, Prevention and Remediation of Dense and Debris flow Eds. Lorenzini, Brebbia and Emmauouloudis, 7 - 9 giugno 2006, Rhodes, Greece

[34] MCCORMACK R.W., The effect of viscosity in hypervelocity impact cratering AIAA Paper, 1969, 75-1.

[35] O'Brien J.S., Julien P.J., FulLeRTON W.T., Two - dimensional water flow and mudflow simulation, Journal of Hydraulic Engineering, 1993, 119, 244-261.

[36] Rodriguez C., Blanco A., Garcia R., Comparison of $1 D$ debris flow modelling approaches using a high resolution and non - oscillatory numerical scheme on the finite volume methods, Proc. of the $1^{\text {st }}$ International Conference on Monitoring, Simulation, Prevention and Remediation of Dense and Debris Flow, Eds. Lorenzini and Brebbia, Rhodes, 2006.

[37] RoE P.L. Approximate Riemann solver, parameters vectors and difference schemes Journal of Computational Physics, 43, 1981, 357-372.

[38] Schamber D.R., Katopodes N.D., One - dimensional model for partially breached dams Journal of Hydraulic Engineering, 110, 1984, 1086-1102.

[39] Scotton P., ARManini A., Experimental investigation of roughness effects of debris flow channels $6^{\text {th }}$ Workshop on Two - Phase Flow Prediction, Erlangen, 1992.

[40] ShIEH C.L., JAN C.D., Tsai Y.F., A numerical simulation of debris flow and its applications Natural Hazards, 1996, 13, 39-54.

[41] Sweby P.K., High resolution schemes using flux limiters for hyperbolic conservation laws SIAM Journal of Numerical Analysis, 21, 1984, 995-1011.

[42] Takahashi T. Debris flow International Association for Hydraulic Research, Balkema, Rotterdam, 1991.

[43] TAKAHASHI T, Initiation of flow of various types of debris flow Proc. Second International Conference on Debris Flow Hazard Mitigation: Mechanics, Prediction and Assessment, Eds. Wieczorak and Naeser, Rotterdam, 2000, 15-25.

[44] TaKahashi T., Nakagawa H., Flood / debris flow hydrograph due to collapse of a natural dam by overtopping Journal of Hydroscience and Hydraulic Engineering, 1994, 12, 41-49.

[45] TAKahashi T., NAKagawa H., KuANG S., Estimation of debris flow hydrograph on varied slope bed Proceedings of the Corvallis Symposium, 1987.

[46] Wallis G. B., One-dimensional Two-phase Flow, Mc Graw Hill Book Company, 1962, in particular Par. 3.3 "One-dimensional separated flow in which the phases are considered separately".

[47] WAN Z., WANG Y., Hyper - concentrated flow International Association for Hydraulic Research monograph, The Netherlands, 1984.

[48] Wang Y., Hutter K., A constitutive model of multiphase mixtures and its application in shearing flows of a satured solid-fluid mixtures, Granular Matter, 1(4), 163-181, 1999.

\section{SUMMARY}

To predict floods and debris flow dynamics a numerical model, based on 1D De Saint Venant (SV) equations, was developed. The McCormack - Jameson shock capturing scheme was employed for the so- lution of the equations, written in a conservative law form. This technique was applied to determine both the propagation and the profile of a two - phase debris flow resulting from the instantaneous and complete collapse of a storage dam.

To validate the model, comparisons have been made between its predictions and laboratory measurements concerning flows of water and homogeneous granular mixtures in a uniform geometry flume reproducing dam - break waves. Agreements between computational and experimental results are considered very satisfactory for mature (non - stratified) debris flows, which embrace most real cases. To better predict immature (stratified) flows, the model should be improved in order to feature, in a more realistic way, the distribution of the particles of different size within the mixture.

On the whole, the model proposed can easily be extended to channels with arbitrary cross sections for debris flow routing, as well as for solving different problems of unsteady flow in open channels by incorporating the appropriate initial and boundary conditions.

Key words: Debris flow, dam-break, rheological behaviour of the mixtures, two-phase modelling.

\section{List of Symbols}

$a_{b} \quad$ Bagnold experimental constant [ ]

$c \quad$ celerity $[\mathrm{m} / \mathrm{s}]$

$c_{*} \quad$ bed volumetric solid concentration [ ]

$c_{D} \quad$ drag coefficient []

$c_{l} \quad$ volumetric concentration of water [ ]

$c_{s} \quad$ volumetric concentration of solid phase [ ]

$c_{m}$ maximum concentration of the solid material when packed [ ]

$d_{50}$ mean diameter of granular material [m]

$d s \quad$ spatial step [m]

$d t \quad$ temporal step [s]

$f \quad$ force transmitted by water to a solid particle [N]

$g$ gravity acceleration $\left[\mathrm{m} / \mathrm{s}^{2}\right]$

$i$ channel slope [ ]

$k_{E} \quad$ empiric coefficient of Ghilardi model [ ]

$n$ number of solid particles inside a unitary volume of the mixture [ ]

$q \quad$ specific flow rate of the subtracted solid material $\left[\mathrm{m}^{2} / \mathrm{s}\right]$

$v_{1} \quad$ water mean velocity $[\mathrm{m} / \mathrm{s}]$

$v_{s} \quad$ solid mean velocity $[\mathrm{m} / \mathrm{s}]$

$A \quad$ wetted cross - section area $\left[\mathrm{m}^{2}\right]$

$B \quad$ wetted bed width [m]

$C_{\mathrm{R}}$ Courant number []

$E$ erosion/deposition velocity of granular material $[\mathrm{m} / \mathrm{s}]$

$F \quad$ interaction force between solid and liquid phases [N]

$H$ depth [m]

$J \quad$ water head loss given by Chézy formula []

$Q \quad$ mixture discharge $\left[\mathrm{m}^{3} / \mathrm{s}\right]$

$Q_{l} \quad$ water discharge $\left[\mathrm{m}^{3} / \mathrm{s}\right]$

$Q_{s} \quad$ solid phase discharge $\left[\mathrm{m}^{3} / \mathrm{s}\right]$

$R$ hydraulic radius [m] 
$S_{A} \quad$ Archimedes buoyancy [N]

$S_{i} \quad$ mixture head loss [ ]

$T$ bottom stress force for solid phase [N]

$U$ characteristic velocity of the mixture $[\mathrm{m} / \mathrm{s}]$

$V \quad$ control volume $\left[\mathrm{m}^{3}\right]$

$W^{c}$, solid phase weight reduced of Archimedes buoyancy $[\mathrm{N}]$

$W_{s} \quad$ solid phase weight [N]

$\alpha^{(2)} \quad$ Jameson artificial viscosity coefficient $[\mathrm{m} / \mathrm{s}]$

$\alpha^{(4)}$ Jameson artificial viscosity coefficient $[\mathrm{m} / \mathrm{s}]$

$\beta \quad$ momentum coefficient []

$\delta \quad$ dynamic friction angle of granular material $\left[{ }^{\circ}\right]$

$\phi \quad$ static friction angle of granular material $\left[{ }^{\circ}\right]$

$\eta \quad$ distance from the channel bottom [m] $\lambda$ linear concentration [ ]

$\vartheta$ bed inclination $\left[{ }^{\circ}\right]$

$\vartheta_{e} \quad$ equilibrium angle $\left[{ }^{\circ}\right]$

$\vartheta_{f} \quad$ energy line angle $\left[{ }^{\circ}\right]$

$\Pi_{1}, \Pi_{2}$ forces on control volume lateral surfaces [N]

$\rho$ mixture volumetric density $\left[\mathrm{kg} / \mathrm{m}^{3}\right]$

$\rho_{l} \quad$ water density $\left[\mathrm{kg} / \mathrm{m}^{3}\right]$

$\rho_{s} \quad$ solid phase density $\left[\mathrm{kg} / \mathrm{m}^{3}\right]$

$\sigma \quad$ generic section width [m]

$\sigma_{n}$ normal stress along failure surface for solid phase [Pa]

$\sigma_{s}$ normal stress along surface perpendicular to motion for solid phase [Pa]

$\tau_{\text {lim }} \quad$ shear stress in limit equilibrium conditions $[\mathrm{Pa}]$ 
